\title{
Mentoria em contexto
}

\section{Mentoring in context}

\author{
Lia Marcia Cruz da Silveira' (D) | liadasilveira@gmail.com

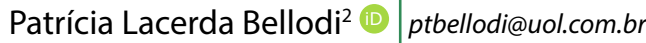 \\ Rosiane Viana Zuza Diniz ${ }^{3}$ (D) rosianevzdiniz@gmail.com \\ Denise Herdy Afonso 4 (D) deniseherdy@gmail.com
}

"Que a importância de uma coisa não se mede com fita métrica nem com balanças nem barômetros etc. Que a
importância de uma coisa há que ser medida pelo encantamento que a coisa produza em nós"

(Manoel de Barros, p. 43)'

A mentoria, relação de orientação e suporte entre um profissional experiente e um iniciante, tem sido reconhecida como importante estratégia de desenvolvimento profissional e pessoal na formação médica, beneficiando mentores e mentorados. Além do caráter desenvolvimental, a relação de mentoria diminui o estresse emocional, potencializando recursos para o enfrentamento de adversidades.

Embora não nomeada especificamente como mentoria, encontramos nas Diretrizes Curriculares Nacionais (DCN) de Graduação em Medicina², publicadas em 2014, indicativos coerentes com esse conceito. Citamos, como exemplo, dois trechos em destaque nas DCN:

Art. $7^{\circ} \mathrm{Na}$ Educação em Saúde, o graduando deverá corresponsabilizar-se pela própria formação inicial, continuada e em serviço, autonomia intelectual, responsabilidade social, ao tempo em que se compromete com a formação das futuras gerações de profissionais de saúde, e o estímulo à mobilidade acadêmica e profissional, objetivando:

IV - aprender em situações e ambientes protegidos e controlados, ou em simulações da realidade, identificando e avaliando o erro, como insumo da aprendizagem profissional e organizacional e como suporte pedagógico;

Art. 29. A estrutura do Curso de Graduação em Medicina deve:

$V$-criar oportunidades de aprendizagem, desde o início do curso e ao longo de todo o processo de graduação, tendo as Ciências Humanas e Sociais como eixo transversal na formação de profissional com perfil generalista [...].

No artigo 70, identificamos a valorização de um processo educacional que desenvolva o autoconhecimento e a autonomia do educando da mesma forma que explicita a importância do ambiente de aprendizagem seguro para que a reflexão sobre a prática aconteça de forma sistematizada e orientada. No artigo 29, destaca-se a importância de a gestão do curso, de forma intencional e transversal, oportunizar o desenvolvimento pessoal e profissional de forma ampla e individualizada.

Nesse contexto, a reflexão sobre a mentoria apresentada no suplemento é coerente e apoia os objetivos da Associação Brasileira de Educação Médica (Abem) para a melhoria da formação médica, desde o momento de ingresso na escola médica.

A pandemia do novo coronavírus, com as necessárias medidas de controle, afetou médicos e profissionais da saúde na linha de frente do cuidado, com intensa sobrecarga física e emocional, impactando fortemente também a formação médica. Em um período turbulento, de interferência drástica nas atividades das escolas médicas, as ações de suporte, entre elas a mentoria, tornaram-se ainda mais relevantes.

A divulgação científica sobre mentoria pela Revista Brasileira de Educação Médica (RBEM), por meio de um suplemento especial, visou estimular a reflexão sobre as potencialidades dessa intervenção a qual, ao mesmo tempo que incrementa a formação, por meio das trocas intergeracionais, promove saúde mental, por meio de relações próximas, empáticas e solidárias.

Considerando a diversidade de públicos, práticas e contextos nos quais pode ser desenvolvida, buscou-se com essa iniciativa

\footnotetext{
1 Universidade Federal do Rio de Janeiro, Rio de Janeiro, Rio de Janeiro, Brasil.

2 Universidade de São Paulo, São Paulo, São Paulo, Brasil.

${ }^{3}$ Universidade Federal do Rio Grande do Norte, Natal, Rio Grande do Norte, Brasil.

${ }^{4}$ Universidade do Estado do Rio de Janeiro, Rio de Janeiro, Rio de Janeiro, Brasil.

Recebido em 07/05/21; Aceito em 07/05/21.
} 
dar visibilidade às práticas brasileiras relacionadas à mentoria e valorizá-las, no âmbito das escolas médicas e/ou residência médica, acolhendo tanto a experiência de programas de mentoria consolidados quanto daqueles em processo de desenvolvimento.

Neste suplemento, o leitor interessado pelo tema encontrará experiências e reflexões sobre desafios e potencialidades da mentoria, impacto na formação dos alunos, componentes éticos da relação mentor-mentorado-instituição de ensino, necessidade de desenvolvimento docente específico para a atividade e modelos de inserção curricular dela.

\section{MENTORIAS: EXPERIÊNCIAS E REFLEXÕES DA COMUNIDADE ACADÊMICA}

A proposta do suplemento parece ter estimulado aqueles que se dedicam à mentoria em suas instituições a contar sua história, sejam eles mentores, alunos, residentes e/ ou coordenadores de programa.

Recebemos 56 artigos para avaliação, sendo 40 relatos de experiência, dez artigos originais, três ensaios e três revisões sistemáticas. Desse total, 29 estão publicados neste suplemento.

Programas de mentoria estão acontecendo em todas as regiões do Brasil e nas diferentes regionais da Abem (Figura 1).

Recebemos manuscritos de 38 instituições: 27 públicas e 11 privadas.

Em relação às linhas temáticas, $75,0 \%$ dos artigos abordaram a mentoria na graduação médica; $8,9 \%$, a mentoria por pares; 5,4\%, o desenvolvimento docente para mentoria; $5,4 \%$, a mentoria reversa; 3,6\%, aspectos relacionados à implantação de programas de mentoria; e 1,8\%, a mentoria na residência médica.

Figura 1. Artigos submetidos por regional da Abem

\section{NOSSAS PERCEPÇÕES}

A mentoria na formação médica brasileira, embora relativamente recente, mostra-se viva e atuante, além de produzir encantamento.

O número de artigos e a variedade de experiências nos permitem afirmar que a mentoria é uma prática de crescente aplicação. Seja como programa estruturado ou prática informal, ação institucional ou iniciativa voluntária individual, ou ainda como prática colaborativa entre docentes e ou discentes, a mentoria está presente em diferentes instituições de ensino superior brasileiras.

Os artigos mostram que há um desejo genuíno de cuidar dos futuros médicos com trabalho sério e persistente: há experiências gerando experiência em mentoria, ou seja, a multiplicidade dos "fazeres" nas diferentes escolas produz, em conjunto, um "saber acumulado" sobre a mentoria em si. Mostram ainda a criatividade e resiliência dos diferentes programas, firmes em seu propósito de manter a mentoria acontecendo mesmo de forma remota, em tempos de pandemia.

Contudo, destacam-se os diferentes entendimentos sobre o que seja mentoria, apresentada muitas vezes numa abordagem mais de ensino do que de acompanhamento do desenvolvimento integral da pessoa do educando. Embora a orientação seja um importante componente pedagógico da tarefa do mentor, o foco da mentoria não está na facilitação da aprendizagem de temas ou de práticas, mas sim no educando e nas vivências dele. A mentoria considera as diferentes dimensões que constituem o educando como sujeito ${ }^{3}$, as repercussões em seu desenvolvimento de um processo formativo tensionado, desgastante e estressante, e os recursos de diferentes naturezas para seu enfrentamento.

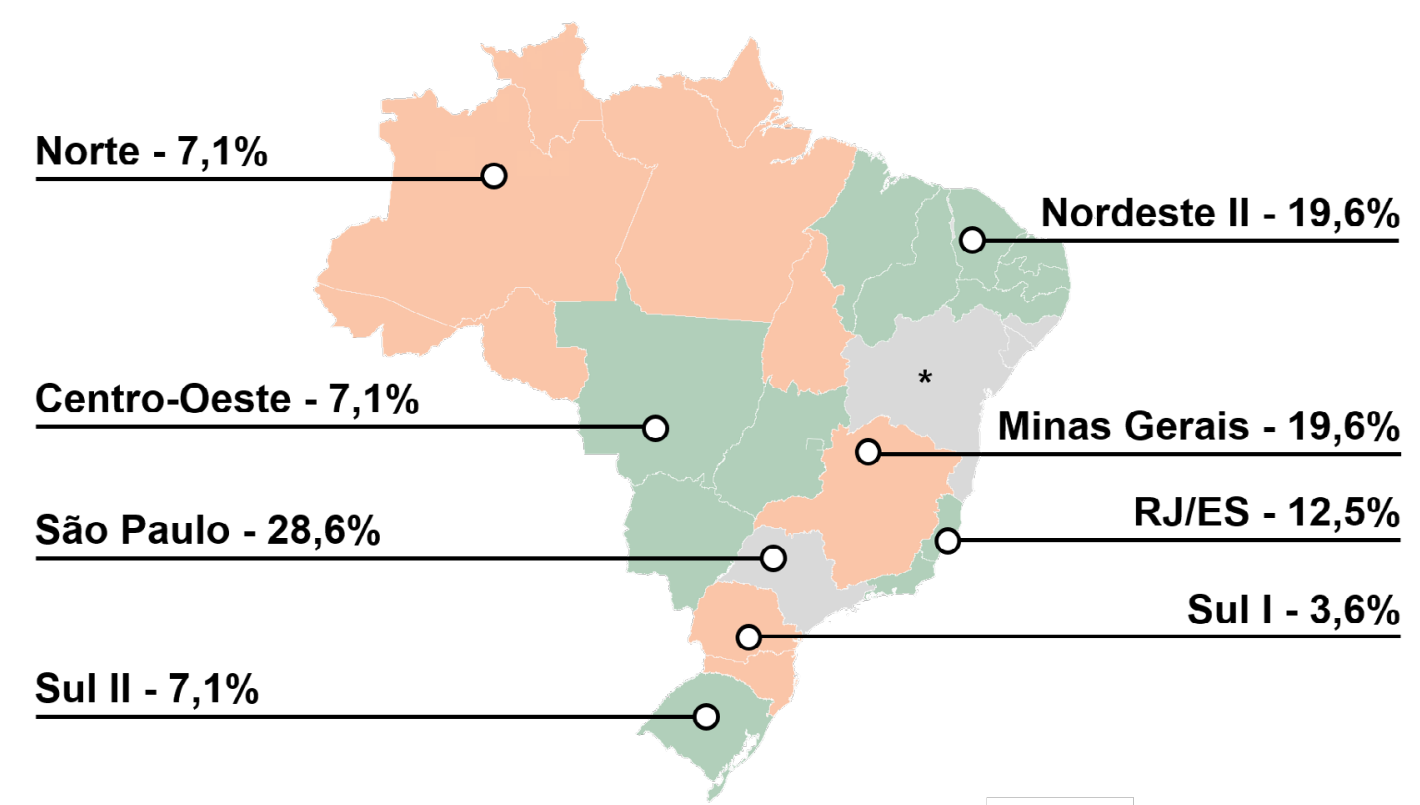

${ }^{*}$ A regional Nordeste I não teve artigos submetidos. 
A tradução de mentoring por tutoria em português pode explicar parte dessa confusão, sendo recente a inserção da palavra mentoria em nossos dicionários ${ }^{4}$. Além disso, práticas de treinamento de determinadas habilidades, conhecidas como coaching, e a supervisão de atividades práticas realizadas por estudantes e residentes, denominada preceptoria, também se misturam com alguns aspectos da mentoria ${ }^{5}$, mostrando a necessidade de definição de um solo comum conceitual para o caminhar da atividade ${ }^{6}$.

Os artigos mostram que o caminho para o estabelecimento de um programa de mentoria de sucesso, isto é, aquele que consegue estruturar espaços para que relações satisfatórias de mentoria aconteçam de forma regular ao longo do tempo, não é percorrido rapidamente. Nesse sentido, as instituições de ensino têm um papel fundamental nos processos de estruturação, apoio, acompanhamento e reestruturação dos programas, de modo a permitir a continuidade da mentoria.

Muitas e diferentes são as necessidades dos alunos e residentes, e muito se espera da mentoria. Jean Rhodes ${ }^{7}$, importante pesquisadora em mentoria para jovens, lembra que "fervor sem infraestrutura" (p. 106) gera frustração, isto é, não basta apenas desejar a proposta e acreditar intensamente nela. Se as etapas de estruturação não forem percorridas com cuidado, especialmente a de desenvolvimento docente para o papel de mentor, rapidamente se poderá caminhar da onipotência para a impotência.

Aprender com o exercício da mentoria implica a promoção de espaços de reflexão sobre a prática, por meio de encontros regulares entre os mentores, para a identificação de problemas e a construção de soluções. Implica também, especialmente, estabelecer um canal com os alunos aberto ao feedback, essencial para o aprimoramento dos processos e resultados dessa intervenção.

A boa formação em mentoria se orienta pelo Relatório Delors ${ }^{8}$ para a Organização das Nações Unidas para Educação, a Ciência e a Cultura (United Nations Educational, Scientific and Cultural Organization - Unesco), da Comissão de Educação para o século XXI, que aponta a necessidade de uma aprendizagem ao longo de toda vida fundamentada em quatro pilares: aprender a conhecer, aprender a ser, aprender a fazer e aprender a conviver. É preciso compreender em profundidade os princípios da atividade (conhecer), ter atributos pessoais (ser) e exercitar habilidades para o papel de mentor (fazer). É preciso ainda, e especialmente, aprender com a experiência, a própria, e também a de outros (conviver). Afinal, não é essa a essência da própria mentoria?
Desejamos que vocês encontrem neste suplemento experiências que traduzam essa essência. E que essas experiências acolham, inspirem, orientem e, por que não dizer, sejam "mentoras" de novos e criativos projetos na área.

Para finalizar, deixamos aqui registrado o nosso agradecimento a todas as pessoas que, generosamente, doaram seu tempo, expertise, motivação e alegria, contribuindo amorosamente para que este suplemento fosse realidade. Nosso agradecimento especial aos avaliadores que prontamente atenderam ao chamado e à diretoria da Abem que nos confiou essa editoria. Dedicamos este suplemento aos alunos e aos seus mentores por acreditarem ser possível desenvolverem-se juntos, valorizando a história e as experiências dela derivadas, vivenciando o hoje e, especialmente, esperançando o futuro.

\section{CONTRIBUIÇÃO DAS AUTORAS}

As autoras produziram o editorial de forma colaborativa. Lia Marcia Cruz da Silveira e Patrícia Lacerda Bellodi foram responsáveis pela ideia e conceituação do editorial, além da redação do rascunho e revisão da versão final do texto. Rosiane Viana Zuza Diniz e Denise Herdy Afonso participaram da revisão crítica do rascunho e da versão final do texto.

\section{CONFLITO DE INTERESSES}

As autoras declaram não haver conflito de interesses.

\section{FINANCIAMENTO}

As autoras declaram não haver financiamento.

\section{REFERÊNCIAS}

1. Barros M. Memórias inventadas: a segunda infância. São Paulo: Planeta; 2006.

2. Brasil. Resolução n 3, de 20 de junho de 2014. Diretrizes Curriculares Nacionais de Graduação em Medicina. Diário Oficial da União; 23 jun 2014. Seção 1.

3. Freire P. Pedagogia da autonomia. Saberes necessários à prática educativa. 9a ed. São Paulo: Paz e Terra; 1998. p.159-65.

4. Houaiss A. Grande dicionário Houaiss da língua portuguesa [acesso em 18 maio 2021]. Disponível em: https://houaiss.uol.com.br.

5. Bellodi PL. Tutor. In: Bellodi PL, Martins MA. Tutoria: mentoring na formação médica. São Paulo: Casa do Psicólogo; 2005. p. 69-86.

6. Botti SHO, Rego S. Preceptor, supervisor, tutor e mentor: quais são seus papéis? Rev Bras Educ Med. 2008;32(3):363-73.

7. Rhodes J. Stand by me: the risks and rewards of mentoring today's youth Cambridge: Harvard University Press; 2002.

8. Delors J. Educação: um tesouro a descobrir. Relatório para a UNESCO da Comissão Internacional sobre Educação para o século XXI. São Paulo: Cortez; 1998. p. 89-101. 